\title{
Dynamic Changes of Fenestrations in Choriocapillaries
}

\author{
RISEI ISHIBASHI, ARATA SUGITA AND HISAHARU YOSHIOKA \\ Department of Ophthalmology, Kurume University School of Medicine, \\ Kurume, 830 Japan
}

Received for publication November 26, 1984

\begin{abstract}
Summary: The ultrastructure of choriocapillaries from dark-adapted eyes of Uroloncha Striata Domestica was studied with a freeze-fracture replica technique. Fenestrations were observed on the surface of the cleavage plane of the choriocapillary endothelial membrane. Fenestrations of endothelial cells facing Bruch's membrane in controls were densely distributed and clearly separated from the non-fenestrated areas. The average diameter of the fenestrations was $71 \pm 6 \mathrm{~nm}$ and the average number of fenestrations was $39.1 \pm 6.0 / \mu \mathrm{m}^{2}$. In the dark-adapted eye, the fenestrations of endothelial cells facing Bruch's membrane were scattered and it was impossible to clearly distinguish the fenestrated areas from non-fenestrated areas. The average diameter of the fenestrations was $70 \pm 6 \mathrm{~nm}$ and the average number of fenestrations was $27.4 \pm$ $7.6 / \mu \mathrm{m}^{2}$. The difference in fenestration density between control and adapted eyes was significant $(\mathrm{P}<0.01)$. These findings indicate that the distribution pattern of fenestrations in endothelial cells of choriocapillaries is dynamic and results in a decrease in vascular permeability of the choriocapillaries in the dark.
\end{abstract}

Key words: fenestration - choriocapillaries - freeze fracture-dark adaptation - birds

\section{Introduction}

Choriocapillaries supply the outer retina with oxygen, which diffuses across Bruch's membrane, through the retinal pigment epithelium and into the outer neural layer of the retina, particularly the rods and cones. Morphologically, choriocapillaries belong to the fenestrated type and the endothelial cells of choriocapillaries have numerous fenestrations. The fenestrations in the choriocapillaries are not the same in all regions of the fundus. Sugita et al. (1982) demonstrated that the fenestrations differed in diameter and distribution from the macula to the equator to the periphery. Other authors (Ishimura et al. 1976; Yoshimoto and Murata, 1979; Hattori, 1980; Federman, 1982.) also demonstrated that fenestrations were not static but were af fected by pathological changes.

It is not established if these fenestrations are affected by physiological conditions in the region of the choroid. The purpose of this paper is to clarify the effect of dark adaptation on the fenestrations of choriocapillaries.

\section{Materials and Methods}

Fifteen adult male birds (Uroloncha Striata Domestica), weighing $13 \mathrm{~g}$, were used for this experiment. Enucleation was performed under a red light after three hours of dark adaptation. The eyeballs were fixed for ten minutes in a mixture of $2.5 \%$ glutaraldehyde and $2 \%$ paraform- 
aldehyde in $0.1 \mathrm{M}$ cacodylate buffer $(\mathrm{pH}$ 7.4).

The eyeballs were bisected at the equator with a razor blade and tissue from the posterior half of the eyeball around the foveola was removed and cut into small pieces. The pieces were fixed for two hours in the same fixative that was described above and then soaked in $40 \%$ glycerol in phosphate buffer ( $\mathrm{pH} \mathrm{7.2)} \mathrm{for} \mathrm{one}$ hour, frozen in liquid Freon 22 and transferred immediately to liquid nitrogen. The fracture was performed in a freeze etching apparatus (FD2A) at a pressure of $5 \times 10^{7}$ Torr. The cleaved surfaces were shadowed with platinum-palladium and strengthened with vacum-evaporated carbon. The replicas were observed with a H-500 electron microscope.

The controls were treated in the same manner, except the enucleation was performed after one hour in darkness and three hours in light.

Some tissue sections were fixed for two hours in $2 \%$ osmic acid, dehydrated in graded alcohol and embedded in Epok 812. Ultrathin sections were cut with a PorterBlum ultramicrotome and stained with uranium acetate and lead citrate. Observations were made using a H-500 electron microscope.

\section{Results}

Choriocapillaries of control Uroloncha Striata Domestica were composed of endothelial cells and pericytes. The cell bodies of endothelial cells were on the scleral side and surrounded by the common basement lamina of pericytes. Fenestrations of choriocapillaries usually faced Bruch's membrane and had one or two diaphragms (Fig. 1). Numerous fenestrations were observed on the surface of the cleavage plane of the choriocapillary endothelial membrane by the freeze fracture technique. Fenestrations of endothelial cell surfaces near Bruch's
TABLE 1

Diameter and number of fenestrations in choriocapillaries

\begin{tabular}{lcc}
\hline & $\begin{array}{c}\text { diameter } \\
(\mathrm{nm})\end{array}$ & $\begin{array}{c}\text { number } \\
\left(1 \mu \mathrm{m}^{2}\right)^{*}\end{array}$ \\
\hline control eyes & $71 \pm 6$ & $39.1 \pm 6.0$ \\
dark adapted eyes & $70 \pm 6$ & $27.4 \pm 7.6$ \\
\hline
\end{tabular}

$* \mathrm{P}<0.01$

membrane were densely distributed and clearly separated from the non-fenestrated area (Fig. 2). The average diameter of fenestrations was $71 \pm 6 \mathrm{~nm}$ and the average number of fenestrations per $1 \mu \mathrm{m}^{2}$ was 39. $1 \pm 6.0$ (Table 1).

In the dark adapted eye, fenestrations were usually observed facing Bruch's mem. brane, they did not differ from those in controls by microscopic examination (Fig. 3). Fenestrations of the choriocapillaries had one or two diaphragms (Fig. 4). Using the freeze fracture technique, fenestrations were usually observed facing Bruch's membrane (Fig. 5) and numerous fenestrations were found on the surface of the cleavage plane of the choriocapillary endothelial membrane (Fig. 6, 7). The fenestrations in endothelial cells facing Bruch's membrane were scattered and thus it was impossible to clearly separte the fenestrated and non-fenestrated areas. The average diameter of the fenestrations was $70 \pm 6$ $\mathrm{nm}$ and the average number of fenestrations per $1 \mu \mathrm{m}^{2}$ was $27.4 \pm 7.6$ (Table 1 ).

The difference in density of fenestrations between adapted eyes and control eyes was statistically significant $(p<0.01)$.

\section{Discussion}

True capillaries are classified as continuous capillaries, fenestrated capillaries or discontinuous capillaries. Fenestrated capillaries have numerous fenestrations on 
the endothelial membrane and the fenestrations are related to the permeability to nutrients.

Recently, the deep-etching replica method clearly revealed the size of molecules which can pass through fenestrations. The fenestrations of endothelial cells change under pathological conditions. For example, Ishimura et al. (1976) reported that the number and density of capillary pores in the thyroid body were greater in TSHtreated mice than in control mice. Yoshimoto and Murata (1979) showed that the average number of fenestrations in the choriocapillaries was $35.0 / \mu \mathrm{m}^{2}$ in controls and $49.7 / \mu \mathrm{m}^{2}$ in spontaneously hypertensive rats. Hattori (1980) studied the fenestrations of endothelial cells of choriocapillaries in guinea pig under normal conditions and with experimental autoimmune uveoretinitis (EAU). The average diameter was $65.0 \mathrm{~nm}$ in controls and $70.6 \mathrm{~nm}$ in EAU. Federman (1982) reported that in human eyes with choroidal melanomas, there is a lower frequency of fenestration formation by endothelial cells of the choriocapillaries.

These results demonstrate that fenestration of endothelial cells in choriocapillaries changes under some pathological conditions. However it has never been determined whether the fenestrations in choriocapillaries change with physiological conditions.

The effect of dark adaptation on fenestration of choriocapillaries was investigated on Uroloncha Striata Domestica since these birds are diurnal, possess only a cone system, and are easily effected by dark adaptation. The present study demonstrated that fenestration of endothelial cells in the choriocapillaries was dynamic in nature.

Zuckerman and Weiter (1980) observed that retinal oxygen consumption in bullfrogs is higher under dark conditions. The bullfrogs have rod retina only and are hyperactive in the dark, which could increase oxygen consumption. Uroloncha Striata
Demestica have cone retina only, are hyperactive in light, and may be hypoactive in dark.

Amemiya (1983) studied the reaction of pecten oculi with alkaline phosphatase and revealed that birds with only cone retina have no retinal function on darkness and retinal metabolism is depressed in the dark. Weiter and Zuckerman (1980) measured oxygen consumption in each retinal layer and found that the photoreceptor accounts for most of the retinal oxygen consumption.

Based on these results, the function of the photoreceptor in Uroloncha Striata Demestica, which has a cone retina only, is decreased and retinal metabolism is also depressed in the dark. Therefore oxygen consumption of the photoreceptor should be depressed, and thus oxygen supply to the photoreceptor from choriocapillaries is not necessary. The density of fenestrations in choriocapillaries, associated with molecular passage of nutrients, may then be decreased.

\section{References}

Alder, V. A., Cringle, S. J. and Constable, I. J. (1983). The retinal oxygen profile in cats. Invest. Ophthalmol. Vis. Sci. 24, 30-36.

Amemiya, T. (1983). Electron histochemical study of the dark adapted retina. The Cell. 15, 495-500.

Clementi, F. and Palade, G. E. (1969). Intestinal capillaries. I. Permeability to peroxidase and ferritin. J. Cell Biol. 41, 33-58.

Deollery, C. T., Bulpitt, C. J. and Kohner, E. M. (1969). Oxygen supply to the retina from the retinal and choroidal circulations at normal and increased arterial oxygen tensions. Invest. Ophthalmol. 8, 588-594.

Federman, J. L. (1982). The fenestrations of the choriocapillaris in the presence of choroidal melanoma. Trans. Am. Ophthalmol. Soc. 80, 498-516.

HAtToRI, K. (1980). Morphometric study of fenestrations of choriocapillaris. Acta Soc. Ophthalmol. Jpn. 84, 977-986. 
Hogan, M. J., Alvarado, J.A. and Wednel, J.E. (1971). Choroid, Histology of the human eye. p. 320-392. Philadelphia, London, Tronto: W. B. Saunders Company.

Ishimura, K., Окамото, H. and Fujita, H. (1976). Freeze-etching studies on ultrastructural changes of endothelial cells in the thyroid of normal, TSH-treated and thyradin-treated mice. Cell. Tiss. Res. 175, 313-317.

Karnovsky, M. J. (1967). The ultrastructural basis of capillary permeability studied with peroxidase as a tracer. J. Cell Biol. 35, 213236.

LANDERS, M.B. III (1978). Retinal oxygenation via the choroidal circulation. Trans. Am. Ophthalmol. Soc. 76, 528-556.

MAJNo, G. (1965). Ultrastructure of the vascular membrane, Handbook of physiology (ed. by Hamilton, W. B.). American Physiological Society, Washington, D. C., Sec. 2, Vol. 3, 2293-2373.

Matsuoka, T. (1983). Freeze-fracture studies on the choriocapillary endothelium 1. Three- dimensional visualization of the fenestral diaphragm. Acta Soc. Ophthalmol. Jpn. 87, 1065-1076.

Ohruma, M. and Nishiura, M. (1973). Freezefracture and freeze-etch replica of the eye. I. Replica of the choriocapillary, Bruch's membrane and retinal pigment epithelium. Folia Ophthalmol. Jpn. 84, 197-209.

Sugita, A., Hamasaki, M. and Higashi, R. (1982). Regional difference in fenestration of choroidal capillaries in Japanese monky eye. Jpn. J. Ophthalmol. 26, 47-52.

Weiter, J. J. and Zuckerman, R. (1980). The influence of the photoreceptor-RPE complex on the inner retina. Am. Acad. Ophthalmol. 87, 1133-1139.

Yoshimoto, H. and Murata, M. (1979). A freezefracture study on choriocapillaries in spontaneously hypertensive rats. Ophthalmic Res. 11, 177-191.

Zuckerman, R. and Weiter, J. J. (1980). Oxygen transport in the bullfrog retina. Exp. Eye Res. 30, 117-127. 


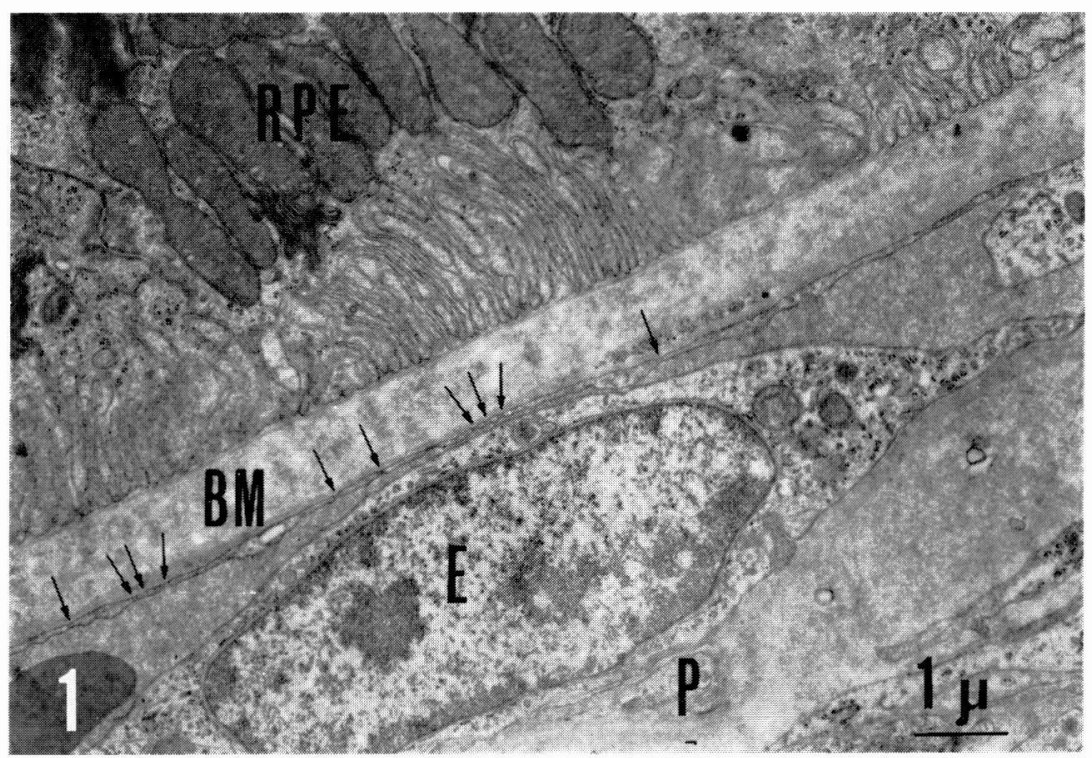

Fig. 1. Electron micrograph of a control eye. The fenestrations of endothelial cells in the choriocapillaries are usually observed on the side near Bruch's membrane (arrows) ( $\times 11000)$.

RPE : retinal pigment epithelium BM: Bruch's membrane.

$\mathrm{P}$ : pericyte $\mathrm{E}$ : cell body of endothelial cell

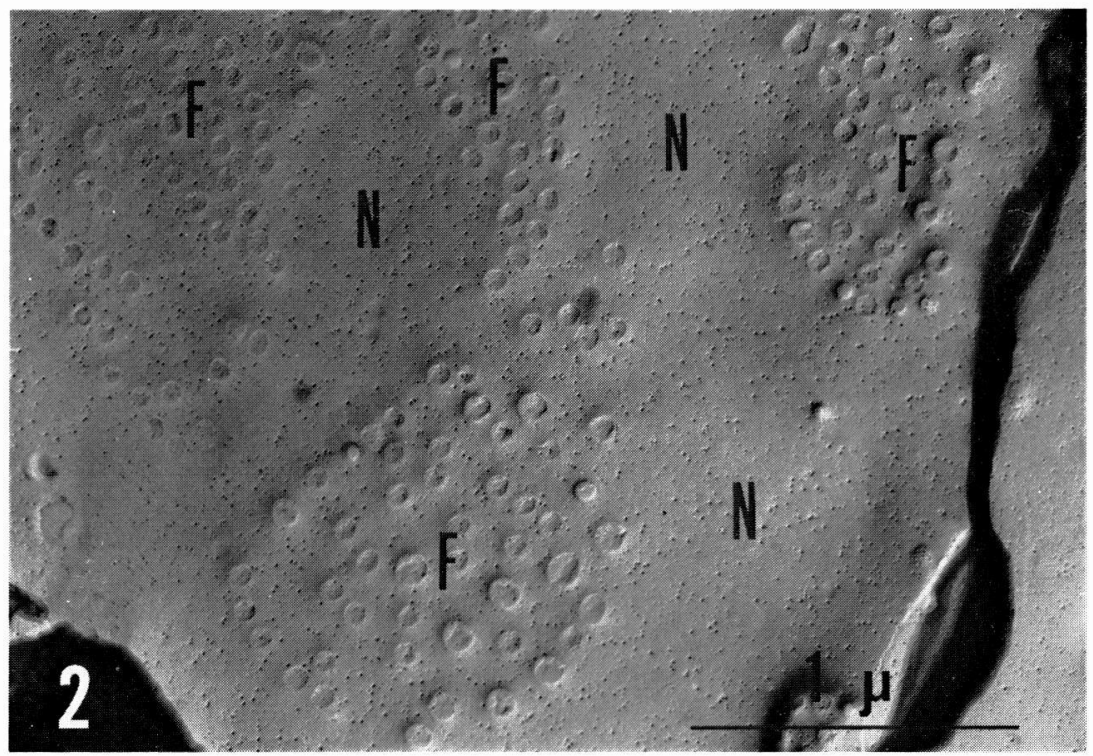

Fig. 2. A freeze-fractured replica of a control eye. The fenestrated $(\mathrm{F})$ and non-fenestrated areas $(\mathrm{N})$ are clearly seen on the endothelial cell of the choriocapillaries. $(\times 38000)$. 


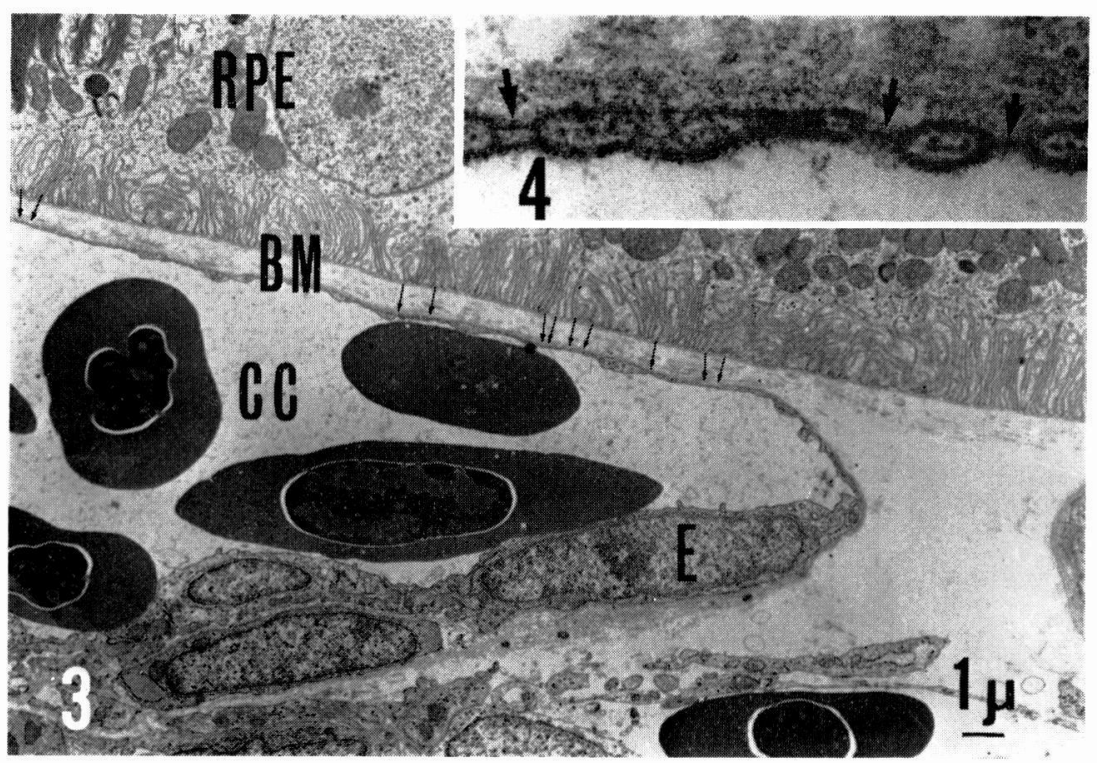

Fig. 3, 4. Electron micrograph of a dark adapted eye. Each fenestration is closed by one or two diaphragms (arrows) $(\times 45000$, Inset $\times 80000$ )

RPE : retinal pigment epithelium BM: Bruch's membrane

CC : Choriocapillary E : cell body of endothelial cell

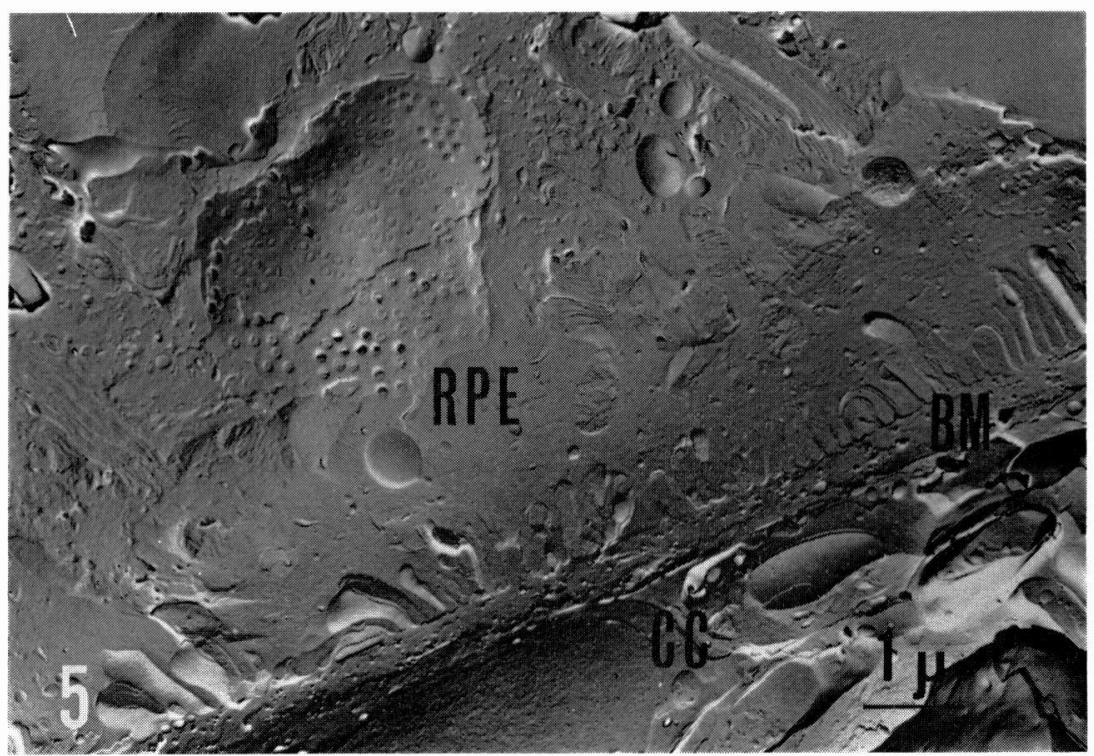

Fig. 5. A freeze-fractured replica of a dark adapted eye.

$(\times 11000)$

RPE : retinal pigment epithelium BM: Bruch's membrane $\mathrm{CC}$ : choriocapillary 


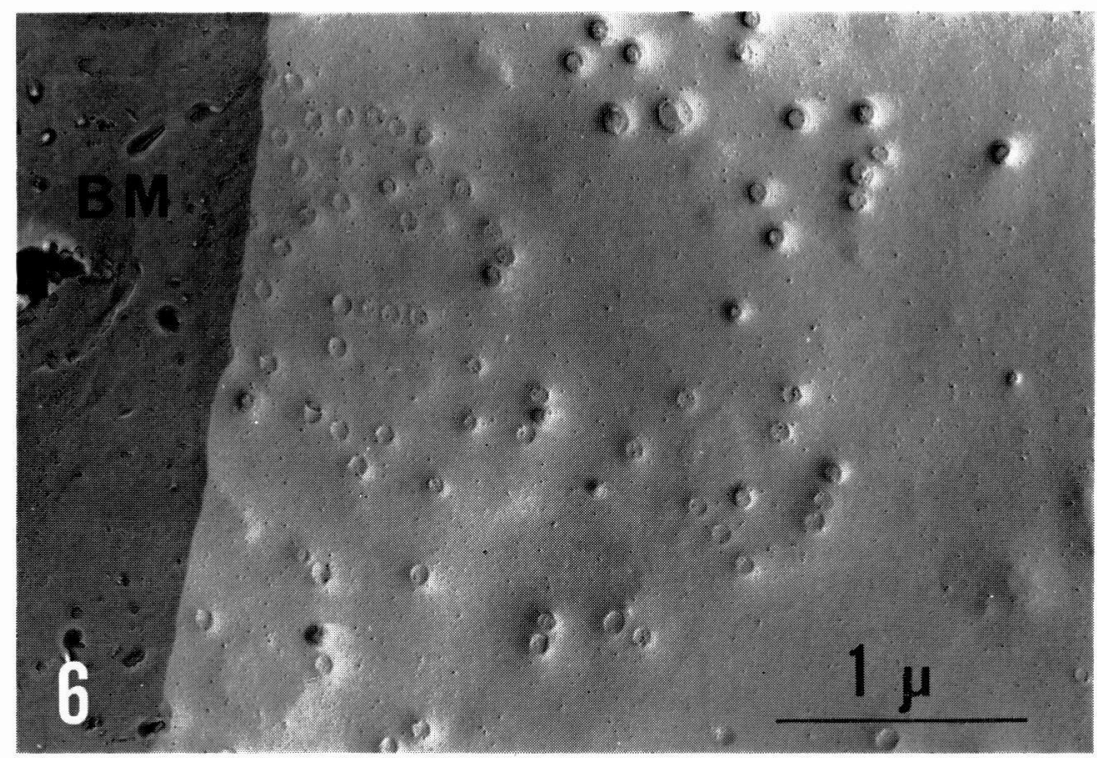

Fig. 6. A freeze-fractured replica of a dark adapted eye. It is impossible to clearly differentiate the fenestrated area from the non-fenestrated area $(\times 34000)$.

BM : Bruch's membrane

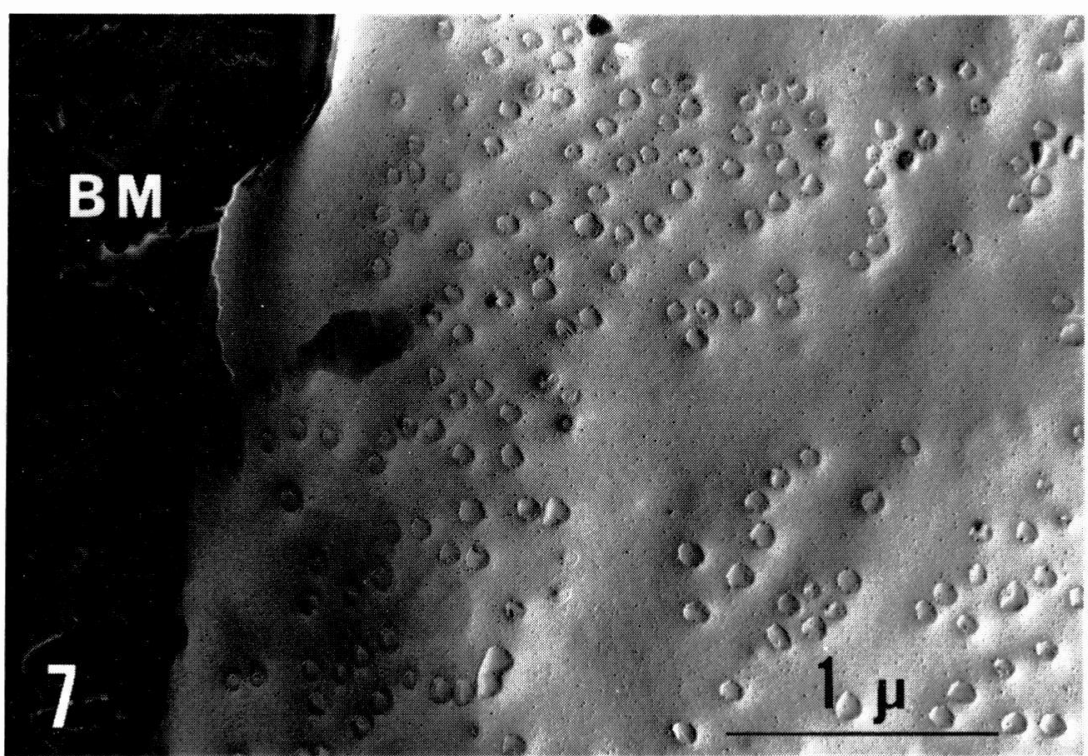

Fig. 7. A freeze-fractured replica of a dark adapted eye. Numerous fenestrations are seen but it is impossible to clearly differentiate the fenestrated area from the non-fenestrated area

BM : Bruch's membrane 